\title{
Alcances preliminares para la aplicación de la Lex Petrólea en el Perú
}

\author{
Andrés Talavera C. \\ Manuel Ferreyros
}

En el presente artículo, los autores exploran una de las variantes de la Lex Mercatoria, la LexPetrólea, mencionando algunas de sus reglas y principios recogidos en la jurisprudencia arbitral internacional. Asimismo, proponen el ingreso de la Lex Petróleaa nuestro ordenamiento jurídico, a efectos de nutrir y complementar la regulación de las operaciones petroleras en el Perú. Para ello, analizan cuáles son algunas de las formas en que la Lex Petrólea puede ser incorporada a nuestro ordenamiento jurídico y por ende puede ser aplicable a las relaciones contractuales vinculadas a operaciones petroleras.

\footnotetext{
*Asociado del Estudio Bullard, Falla y Ezcurra.

** Practicante del Estudio Bullard, Falla y Ezcurra. Estudiante de último año de Derecho, Pontificia Universidad Católica del Perú.
} 


\section{Alcances preliminares para la aplicación de la Lex Petrólea en el Perú}

\section{Introducción}

La Lex Mercatoria es un tema sobre el cual se ha escrito de forma abundante, y que hasta el día de hoy genera una intensa controversia teórica. Actualmente y conforme las operaciones mercantiles y de inversión adquieren mayor difusión, la realidad comercial internacional pone más énfasis en la aplicación de los usos y prácticas comunes a las relaciones contractuales de determinadas plazas. Estas prácticas basadas en la costumbre internacional, forjan progresivamente un conjunto de reglas y principios de relevancia jurídica que son denominadas comúnmente comoLex Mercatoria.

La Lex Mercatoriaes entonces un ser vivo en constante evolución y transformación. Esto ha llevado a que incluso se generen subtiposde normas basadas en los usos y prácticas de actividades particulares vinculadas a una determinada plaza comercial. Tal es el caso de la Lex Constructionis, para la actividad de construcción, la Lex Electrónica, para el intercambio informático, o la Lex Sportiva, que trata el derecho deportivo internacional, entre varias otras ${ }^{1}$. Estas funcionan como un tipo de lexspecialis sobre la materia, complementado las regulaciones de los contratos de la plaza por sobre los principios generales y otros usos y prácticas más generales de la Lex Mercatoria.

Una de las vertientes evolutivas de esta Lex Mercatoria, quizá aquella con mayor desarrollo en la práctica internacional, es la Lex Petrólea. A pesar de ser un tema de enorme y creciente relevancia, se ha escrito e investigado poco al respecto en nuestro país. El marco legal que regula tales operaciones ha tenido un desarrollo considerable $y$, a la par, existe un significativo caudal de arbitrajes internacionales relacionados con operaciones de inversión petrolera a escala trasnacional. La Lex Petrólea es hoy en día uno de los desarrollos más importantes sobre la Lex Mercatoria, y ha llevado a un universo propio de reglas, principios y regulaciones que merecen ser analizados.

El presente artículo propone una primera vía de ingreso de esta Lex Petróleaa nuestro ordenamiento jurídico peruano, a efectos de nutrir y complementar la regulación de las operaciones petroleras en el Perú. Para ello, realizaremos un recuento del surgimiento histórico de la Lex Petrólea en los casos de expropiación en el Medio Oriente durante la década de 1970. Luego, esbozaremos cuál ha sido el desarrollo teórico de la Lex Mercatoria y, en particular, de la Lex Petrólea. En tercer lugar, mencionaremos, en forma resumida, algunas de las reglas y principios contenidos dentro de la Lex Petrólea, recogidos en la jurisprudencia arbitral internacional. Finalmente, analizaremos cuáles son algunas de las formas en que la Lex Petróleapuede ser incorporada a

\footnotetext{
${ }^{1}$ Moreno, José Antonio. "El debate sobre el Derecho No Estatal y la Lex Mercatoria". En: Revista Forseti, número 1, 2014. Publicado en: http://www.forseti.pe/articulos/el-debate-sobreel-derecho-no-estatal-y-la-lex-mercatoria\#autor
} 
nuestro ordenamiento jurídico y por ende puede ser aplicable a las relaciones contractuales vinculadas a operaciones petroleras.

\section{Desarrollo histórico de la Lex Petrólea}

\subsection{Casos de nacionalización de Libia}

La discusión en el arbitraje internacional en torno a qué ley era aplicable al fondo de una disputa vinculada a contratos de inversión petrolera celebrados entre un estado y una empresa, comenzó a surgir prominentemente en la década de 1970. Los primeros casos notorios en los que se sometió esta pregunta a un tribunal arbitral fueron los tres casos de expropiación de Libia: Libyan American Oil Company - LIAMCO v. Libia $(1977)^{2}$, Texaco Overseas and California Asiatic - TOPCO v. Libia (1977) ${ }^{3}$ y British Petroleum - BP v. Libia (1973) ${ }^{4}$.

Los 3 casos enfrentaban situaciones de hecho similares: se había celebrado un contrato de concesión para la explotación de petróleo entre Libia y una empresa trasnacional. Más adelante, el estado de Libia había decidido nacionalizar tales concesiones, lo cual llevó a procesos arbitrales en los cuales las partes reclamaron la ilegalidad de tales expropiaciones.

Sorprendentemente, en los 3 casos, los 3 tribunales a cargo de resolver las respectivas controversias decidieron de 3 formas distintas. En LIAMCO v. Libia, se consideró que el contrato estaba fundado en el Derecho doméstico de Libia. En TOPCO v. Libia, por el contrario, se decidió "internacionalizar" el contrato y aplicar la costumbre internacional. Finalmente, en BP v. Libia, el tribunal rechazó aplicar al contrato tanto el derecho nacional como el internacional y falló aplicando los principios generales del Derecho.

\subsection{El caso de Kuwait v. Aminoil}

El primer caso en el que se discutió la idea de tal Derecho Trasnacional aplicable a las disputas en inversiones petroleras, que daría nacimiento a la noción de Lex Petrólea, fue el proceso arbitral llevado a cabo entre el estado de Kuwait y la American IndependentOil Company - AMINOIL en $1977^{5}$.

2 Laudo arbitral en el caso Estado de Kuwait v. Libyan American Oil Company del 12 de abril de 1977.

3 Laudo arbitral en el caso Estado de Kuwait v. Texaco OverseasPetroleum Company del 19 de enero de 1977.

$4 \quad$ Laudo arbitral en el caso Estado de Kuwait v. British Petroleum del 10 de octubre de 1973.

$5 \quad$ Laudo arbitral en el caso Estado de Kuwait v. American IndependentOil Company del 24 de marzo de 1982. 
El caso fue también una disputa en torno a la legalidad de un proceso de expropiación y el monto compensatorio derivado de este. En 1948, Kuwait otorgó a AMINOIL, una empresa estadounidense, una concesión de 60 años para la explotación de petróleo en el que Kuwait recibiría una regalía fija por un determinado volumen de petróleo producido. Asimismo, el contrato de concesión incluía una cláusula de estabilidad que aseguraba a AMINOIL que Kuwait no podría luego modificar los términos del contrato de forma unilateral.

En 1961, Kuwait y AMINOILconvinieron complementar la fórmula de regalías fijas mediante un acuerdo de reparto de las ganancias en partes iguales. En 1973, las partes llegaron a otro acuerdo que volvió a aumentar la parte que recibía el Estado. Tal nuevo acuerdo nunca fue ratificado por el parlamento de Kuwait, pero separadamente las partes acordaron aplicar el arreglo de todos modos.

Finalmente, Kuwait exigió un nuevo aumento a su participación en las ganancias según la "fórmula de Abu Dhabi" que fue acordada en la Organización de Países Exportadores de Petróleo. AMINOIL se rehusó a aceptar la incorporación unilateral de esa fórmula al contrato. Como resultado, en el año 1977, Kuwait nacionalizó la concesión y dispuso una compensación por la expropiación.

AMINOIL inició un proceso arbitral en el que reclamó que la expropiación violaba la cláusula de estabilidad del contrato, y solicitó una indemnización por 3 billones de dólares. Kuwait por su parte reconvino reclamando montos que,según aquel, AMINOIL le adeudaba en virtud de los acuerdos de 1973 y de la fórmula de Abu Dhabi.

El tribunal arbitral falló a favor de Kuwait en dos puntos importantes. Primero, decidió que la nacionalización era legítima y que no violaba la cláusula de estabilización. En segundo lugar, dio la razón a Kuwait en cuanto a los montos que alegaba que AMINOIL le adeudaba. Sin embargo, el tribunal también decidió otorgar una compensación por la expropiación a AMINOIL mayor a la que había otorgado Kuwait. Tras compensar los montos adeudados por AMINOIL, se otorgó una indemnizaciónpor la expropiación a favor de la empresa de 83 millones de dólares.

En sus alegatos, Kuwait sostuvo que la compensación que debía pagarse por la expropiación debía basarse en el valor neto contable de los activos de la empresa. Según tal Estado, durante la década de los años 70, tras una serie de expropiaciones similares ocurridas en el Medio Oriente, tal criterio se había vuelto la práctica común y había adquirido carácter de costumbre internacional. Estos precedentes habrían ido configurando un cuerpo jurídico consuetudinario, un subtipo de la Lex Mercatoria, para los negocios petroleros trasnacionales. Es decir, los usos y costumbres habían conducido a la formación de una Lex Petrólea.

Tal argumento fue rechazado por el tribunal. En el laudo, el Tribunal consideró que no podía concluirse que los antecedentes que citaba Kuwait fueran comparables y aplicables al caso en cuestión, entre otras razones, porque se había tratado de negociaciones y no procesos arbitrales, porque en tales casos se había otorgado a las 
empresas trato favorable con respecto a relaciones de inversión futuras como parte de las negociaciones, y porque había existido presión económica muy fuerte hacia las empresas. Es decir, los precedentes citados por Kuwait no formaban una práctica común o una costumbre que pudiera usarse para complementar la relación contractual bajo análisis.

Sin embargo, aunque en tal caso se considerara que los hechos no habían generado una Lex Petrólea, aquel fue el primer caso en el que se alegó y discutió la posibilidad de que existiera una costumbre formada por prácticas mercantiles de la industria del petróleo. El caso representó el surgimiento de la Lex Petrólea. A partir de ese momento la Lex Petrólea se iría conformando y cristalizando en un cuerpo jurídico cada vez más delimitado.

\subsection{Desarrollo general de la Lex Mercatoria y la Lex Petrólea}

Desde la década de 1970, la teoría de la Lex Mercatoria ha adquirido fuerza. Si bien la doctrina se mantiene en disputa acerca de si esta es un sistema jurídico autónomo respecto de cualquier sistema nacional o internacional, para fines prácticos tal disputa teórica tiene reducida importancia. La Lex Mercatoria ha continuado siendo de gran importancia para la regulación de contratos mercantiles a nivel internacional, en tanto que tribunales arbitrales han decidido fallar en laudos aplicando la Lex Mercatoria, sea porque las partes pactaron que emplearían los usos y prácticas generales del comercio, porque tal disposición estaba contenida en leyes nacionales, o porque a falta de cualquier otra norma aplicable decidieron remitirse a ella.

Pueden citarse a tales efectos jurisprudencia arbitral relacionada con controversias en diversas actividades comerciales, como el del caso deRevereCopper and Brass, Inc. v Overseas Private InvestmentCorporation ${ }^{6}$, el caso de PabalkTicaretLimitedSirketi v. Norsolor $^{7}$ o el laudo CCl 7375 entre el demandado (cuyo nombre no es revelado) y el Estado de Iran ${ }^{8}$. En los todos los casos citados, el tribunal arbitral falló aplicando la Lex Mercatoriacomo forma de regular la relación contractual, en lugar de una de las leyes nacionales citadas por las partes.

Ya desde el caso citado anteriormente de TOPCO v. Libia, por ejemplo, el tribunal arbitral decidió que la referencia a los principios internacionales del Derecho implicaba que el contrato fuera internacionalizado. Por consiguiente, falló en base a principios y prácticas en el Derecho Internacional, lo cual incorporó en la práctica la Lex Mercatoria. En tal sentido, a pesar de que la Lex Petrólea no fue reconocida como un

$6 \quad$ Laudo arbitral en el caso de RevereCopper and Brass, Inc. V Overseas Private InvestmentCorporation del 24 de agosto de 1978.

$7 \quad$ Laudo arbitral en el caso dePabalkTicaretLimitedSirketi v. Norsolor del 26 de octubre de 1979.

$8 \quad$ Laudo arbitral CCl 7375 en el caso del demandado (nombre no revelado) v. el Estado de Irán del 5 de junio de 1996. 
ordenamiento jurídico autosuficiente y autónomo, apartado de cualquier Derecho nacional o internacional, en la práctica, su incidencia en las relaciones contractuales vinculadas a la industria petrolera puede llegar a ser de mucha utilidad.

Por su parte, la industria del petróleo a nivel trasnacional también cobró fuerza en el último medio siglo. Como resultado directo, el número de controversias en el arbitraje internacional que giran en torno a inversiones petroleras ha aumentado. Ello ha permitido que los puntos de referencia para evaluar la práctica común en la industria del petróleo se hayan multiplicado, y que hoy sea mucho más claro hablar de los usos y prácticas generales de la industria del petróleo como un orden jurídico de reglas y principios que pueden regular las relaciones contractuales en inversiones petroleras. Más adelante comentaremos algunas de tales reglas y principios, recogidos de la jurisprudencia arbitral internacional, que hoy en día puede decirse conforman la Lex Petrólea.

\section{Desarrollo teónico de la Lex Petrólea}

La doctrina está lejos de ser pacífica en torno a la Lex Mercatoria. Para empezar, es difícilesbozar una definición puntual de Lex Mercatoria que sea aceptada de forma universal y unánime. Sin embargo, podemos partir de la siguiente definición: la Lex Mercatoria es un cuerpo jurídico consistente en la práctica y costumbre internacional, compuesto por principios y reglas que regulan las relaciones comerciales internacionales y que no depende necesariamente de algúnordenamiento jurídico nacional.

Este cuerpo jurídico es conformado a partir de una multiplicidad de fuentes, de las cuales las principales son la costumbre y las prácticas comerciales, la jurisprudencia arbitral internacional y las normas comunes a los ordenamientos jurídicos nacionales.

La Lex Petrólea es una especie dentro del género más amplio que es la Lex Mercatoria. En otras palabras, es una ley especial respecto a la ley general que es la Lex Mercatoria. La Lex Petrólea se define, entonces, como el cuerpo de normas que regulan las prácticas comerciales de la industria petrolera internacional en sus diversas formas.

La existencia de una Lex Petrólea se justifica en que la inversión petrolera tiene prácticas características y propias a la plaza, y problemáticas contractuales particulares que requieren soluciones particulares y ajenas a la práctica comercial general. De la misma forma, los arbitrajes nacidos de controversias de inversiones petroleras han formado un género en sí mismo, con soluciones ad-hoc para controversias vinculadas a esta rama comercial.

De la misma manera en que es difícil encontrar una definición universalmente aceptada de la Lex Mercatoria, existe hasta la fecha un debate teórico en la doctrina acerca de sunaturaleza jurídica. Un sector de la doctrina considera que aquella es un ordenamiento jurídico propio, independiente de cualquier ordenamiento nacional o del 
ordenamiento internacional, que rige las relaciones comerciales trasnacionales. Es, en ese sentido, un "tercer sistema legal". Alfredo De Jesús, por ejemplo, señala que los contratos celebrados entre estados y empresas trasnacionales son incorporadas a un orden jurídico autónomo de los órdenes jurídicos nacionales, nacido de las prácticas comunes y consuetudinarias llevadas en el ámbito internacional ${ }^{9}$.

En cambio, otro sector de la doctrina rechaza tal posición, aduciendo que la Lex Mercatoria no puede ser considerada como un ordenamiento jurídico propio. Una de las críticas más fuertes, por ejemplo, es la que proviene de la teoría amparada en el positivismo jurídico, que aduce que la vinculatoriedad que caracteriza a un ordenamiento jurídico solo puede nacer del amparo de la soberanía de un estado que le da reconocimiento y poder vinculante. En el caso del Derecho Internacional, es a través de las reglas de conflicto que se decide qué Derecho nacional es el aplicable (lo cual 'nacionaliza' las relaciones jurídicas internacionales). Según tal crítica, la Lex Mercatoria es simplemente un cuerpo jurídico que puede tener aplicabilidad a relaciones contractuales, siempre y cuando el Derecho nacional le brinde alguna forma dereconocimiento.

No es el objetivo del presente artículo disertar sobre la naturaleza jurídica de la Lex Mercatoria. La importancia fundamental de la Lex Mercatoria no está en su naturaleza teórica como ordenamiento jurídico autónomo o dependiente de un ordenamiento nacional, sino en su funcionalidad práctica como cuerpo jurídico de reglas y principios que sirven para regular/complementar relaciones contractuales a escala trasnacional. Tal funcionalidad ha tenido innegable difusión, y hoy en día la Lex Mercatoria tiene una incidencia fundamental en las relaciones mercantiles y de inversión a nivel internacional.

La Lex Mercatoria, en cualquier caso, se incorpora a las relaciones contractuales de diversas formas. Las partes pueden pactar en sus contratos una remisión a los usos y costumbres internacionales, lo cual implica la aplicación de la Lex Mercatoria. Esta también puede resultar aplicable por una norma de remisión incluida en las leyes nacionales aplicables a la materia. Finalmente, los tribunales arbitrales pueden aplicar la Lex Mercatoria en caso de insuficiencia de las demás normas aplicables, legales o contractuales, como parte de los principios generales del Derecho y de la costumbre internacional.

\section{IV. ¿Cuál es el contenido de la Lex Petrólea?}

Una de las fuentes más importantes de las cuales podemos extraer los principios que conforman la Lex Petrólea es la jurisprudencia arbitral internacional. Como hemos mencionado líneas arriba, en las últimas décadas, gracias a la proliferación de la actividad petrolera trasnacional alrededor del mundo, se ha generado una cantidad mayor de laudos arbitrales en torno a controversias por contratos de inversión en

9 De Jesús, Alfredo, "The prodigious story of the Lex Petrólea and the rhinoceros".En: Transnational Petroleum Law Institute, 2012, p. 8. 
actividades petroleras. Ello permite estudiar cuáles son las reglas y principios que los tribunales arbitrales han recogido y aplicado $y$, por ende, delinear aquellos preceptos que pueden considerarse parte de los usos y prácticas comunes a dicha plaza.

DoanBishop realizó una investigación ${ }^{10}$ en la cual estudió un número amplio de laudos arbitrales internacionales que trataban conflictos nacidos en torno a la inversión petrolera en sus diferentes formas, desde contratos de perforación hasta contratos de suministro. A partir de lo anterior, Bishop encontró los puntos en común de las decisiones arbitrales y esbozó los contenidos principales de la Lex Petrólea que pueden extraerse de ellas. A continuación listamos algunos de los principios más importantes que Bishop halló en su investigación que han adquirido aceptación en la jurisprudencia arbitral internacional.

En cuanto al valor que podrá ser compensado a las empresas accionistas de inversiones petroleras expropiadas, los gobiernos expropiantes han solido argumentar que debe compensarse solamente el valor neto contable de los activos de una empresa. La jurisprudencia reiterada ha rechazado esta postura al considerarla extrema. De la misma forma, los tribunales han rechazado reiteradamente otorgar a las empresas una compensación en base al lucro cesante correspondiente a la explotación de la concesión por toda su vigencia como una postura extrema opuesta. Solo en casos de expropiaciones ilegítimas, como aquellas realizadas de forma discriminatoria o sin justificación de interés público, los tribunales han otorgado tal compensación por el lucro cesante. En casos de expropiaciones realizadas de forma legítima, se ha optado por otorgar indemnizaciones basadas en principios de equidad, generalmente apuntadas a compensar por la inversión en su valor como negocio en marcha.

Otra línea jurisprudencial hallada en los laudos arbitrales es aquella que interpreta las resoluciones de la Organización de las Naciones Unidas como expresión del derecho consuetudinario internacional. En un número de casos, gobiernos han citado resoluciones como la 626 (VII), 1803 y 3201 (SV-VI) para sostener que es un principio del Derecho Internacional el derecho soberano de los estados de explotar sus recursos naturales, de nacionalizar tales recursos y de no ser sujetos a coerción política 0 económica para prevenir el ejercicio de tal derecho. Al respecto, los tribunales han considerado siempre aplicable lo dispuesto por la resolución No. 1803 con respecto al derecho de la empresa expropiada a recibir una compensación adecuada, a pesar de que las demás resoluciones mencionadas no tienen tal disposición expresa. Además de ello, han fallado reconociendo, sin perjuicio de lo reconocido en tales resoluciones, que ellas no excluyen que toda expropiación debe realizarse en cumplimiento de la buena fe contractual y en respeto de los acuerdos y obligaciones contractuales.

Finalmente, un tercer ejemplo de un criterio jurisprudencial fijado en la Lex Petrólea es aquel en torno a las disposiciones contractuales que tratan el descubrimiento de

10 Bishop, Doan, “International arbitration of petroleum disputes: the development of a Lex Petrólea".En: King \& Spalding, 1998. 
reservas de gas natural no asociado. Es frecuente que las partes pacten que en caso que en el proceso de perforación se descubrieran reservas de gas natural no asociado, estas negociarán un acuerdo posterior respecto a su explotación. Al respecto, los tribunales han fallado que ello conlleva a un deber de negociar de buena fe, pero que sin perjuicio de ello no llegar a un acuerdo o rechazar ofertas por parte de la contraparte no constituye una violación de tal acuerdo.

La jurisprudencia es abundante y los principios y/o reglas que pueden derivarse de ella son de mucha utilidad. La Lex Petrólease ha ido nutriendo de este desarrollo jurisprudencial arbitral y ha ido delineando un cuerpo de normas que regulan las prácticas comerciales de la industria petrolera internacional en sus diversas formas. La Lex Petróleaestá allí para suplir, complementar y lograr una continua evolución en las relaciones contractuales vinculadas a la industria petrolera. Veamos a continuación cómo es que dicho cuerpo de normas podría ser aplicado en nuestro ordenamiento jurídico vinculado a dicha plaza.

\section{Incorporación de la Lex Petrólea al ordenamiento jurídico peruano}

La Lex Petrólea está lejos de ser un concepto lejano a nuestro Derecho y propio solamente de contratos trasnacionales. Por el contrario, tiene incidencia directa en el ordenamiento peruano. En el presente artículo analizamos tres posibles vías por las cuales la Lex Petrólea es incorporada y resulta aplicable en nuestro ordenamiento. Estas son: (i) provisiones contractuales que refieren de forma expresa a la práctica y costumbre en la industria petrolera; (ii) la integración de estándares de diligencia vinculados a la industria petrolera internacional en la ejecución de contratos de inversión petrolera; y (iii) disposiciones en leyes aplicables a la explotación petrolera.

\subsection{Estipulaciones contractuales}

Una de las maneras en las que la Lex Petrólea puede ser aplicable a las relaciones contractuales entre las partes es mediante el pacto expreso en el contrato que remita a los usos y prácticas de aceptación generalizada en la industria. Mediante tal fórmula, las partes están estableciendo, dentro de su autonomía contractual, que tal relación seguirá el estándar de aceptación general internacional - es decir, la Lex Petrólea. Cabe mencionar que el límite a tal estipulación será, como es evidente, las normas de orden público del ordenamiento nacional bajo el cual se celebra el contrato.

Es común en los contratos en los que una de las partes es un estado y la otra una empresa de un país extranjero, que se pacte que serán aplicables los usos y prácticas de aceptación generalizada en la industria, sea de forma directa o de forma subsidiaria (es decir, que será aplicable en caso de vacío al respecto en el contrato o en la ley principal). Ello permite que la operación se lleve a cabo según estándares de aceptación generalizada, lo cual en sí mismo es una garantía de que se tiene un marco regulatorio contractual sólido.

\subsection{I nterpretación de los estándares de diligencia}


De manera similar a lo anterior, las partes suelen pactar cláusulas que establecen un cierto estándar de diligencia exigible a cada una de ellas. A efectos de ahorrar costos de transacción o incluso para dotar de cierto dinamismo a este tipo de contratos, las partes aceptan que parte de las prestaciones que serán objeto de sus obligaciones puedan ser definidos a la luz y en aplicación de estándares internacionales generalmente aceptadas y aplicables a la industria petrolera.

Por tanto, en los contratos de inversión petrolera, la Lex Petróleaes la que dotará de contenido específico al estándar aplicable a un contrato. De tal manera, la evaluación de qué supera el estándar de diligencia para un caso concreto no será realizado sobre el vacío, sino sobre la base de los usos y prácticas que conforman la Lex Petrólea. Qué deberá ser considerado como un comportamiento contractualmente exigible 0 no, 0 sobre qué tipo de prestaciones pueden esperarse a efectos de resolver vacíos en las regulaciones de un contrato, ambos podrán determinarse conforme a los estándares determinados a la luz de los principios y reglas de laLex Petrólea.

\subsection{Remisión legal}

Finalmente, una de las maneras en las que la Lex Petrólea puede ser incorporada como norma que rige las relaciones de las partes en materia de inversión petrolera es la remisión a ella desde las normas legales que regulan esta actividad. A través de disposiciones que hagan referencia a la práctica de uso general en la industria del petróleo, el ordenamiento jurídico efectivamente introduce una cláusula que en sí misma, es vacía y debe ser integrada por aquellos principios que conforman la Lex Petrólea.

Como ejemplos ilustrativo de este tipo de remisiones legales pordemos citar la ley que regula los contratos en materia de inversión en hidrocarburos, en particular del petróleo, que es la Ley Orgánica de Hidrocarburos (Decreto Supremo N 042-2005-EM) (en adelante, LOH). El artículo 34 del Texto Único Ordenado de la LOH establece lo siguiente:

"Artículo 34.- La explotación y la recuperación económica de las reservas de Hidrocarburos se llevará a cabo de acuerdo a los principios técnicos y económicos generalmente aceptados y en uso por la industria internacional de hidrocarburos; sin perjuicio del cumplimiento de las normas de protección del medio ambiente."

De forma similar, la cuarta disposición transitoria de la misma ley establece:

“Cuarta.- (...) En lo no previsto por los reglamentos, serán de aplicación las normas y principios técnicos generalmente aceptados y en uso por la industria internacional de hidrocarburos."

A falta de otra norma específica dentro de la misma ley o sus reglamentos o de una disposición contractual que haya regulado una materia de forma específica, las 
disposicionescitadas establecen queson aplicables los principios técnicos y económicos de aceptación y uso general en la industria petrolera, en otras palabras, la Lex Petrólea.

Estas normas de remisión se justifican por la complejidad de las operaciones en la industria petrolera. Resultaría virtualmente imposible 0 de costos de transacción altísimos, que las partes decidieran regular de forma específica todos los detalles y matices de las condiciones técnicas o económicas aplicables a una operación petrolera. Por esa razón, la norma ha adoptado tal fórmula que permite integrar dichos vacíos mediante la remisión a la práctica de la industria internacional de hidrocarburos. En el caso de las inversiones de petróleo ello significa, por su propia definición, una remisión a la Lex Petrólea.

La importancia de estas normas es considerable. Lo que la fórmula contenida en la LOH significa es, en la práctica, un reconocimiento de la Lex Petrólea como la norma subsidiaria a la ley y el contrato. En virtud de nuestra norma de hidrocarburos, un tribunal arbitral está legamente habilitado para remitirse a la Lex Petrólea a efectos de integrar un vacío en la regulación de una operación contractual petrolera, en caso dicho vació no pueda ser cubierto ni por la norma doméstica (en este caso la LOH) ni por el contrato.

\section{Conclusión}

La aplicabilidad de la Lex Petrólea puede nacer de muchas formas, ya sea, como hemos mencionado, a través de estipulaciones contractuales o por normas de remisión aplicables a la actividad petrolera. La Lex Petrólea, además, es también aplicada por tribunales arbitrales a casos particulares en base a posiciones que deciden por la internacionalización de los contratos de inversión, como hemos visto en precedentes citados. Por ende, la Lex Petrólea, como concreción de los usos y prácticas de aceptación generalizada en la industria internacional del petróleo, podría tener una incidencia sumamente importante en los contratos de este tipo en el Perú.

Es importante notar que la Lex Petrólea es un cuerpo jurídico en constante evolución. Conforme la inversión trasnacional en la industria del petróleo continúe, y la técnica jurídica que la acompaña siga su desarrollo técnico así como teórico, la Lex Petrólea podrá continuar cristalizándose como un cuerpo de normas y principios jurídicos adecuados para regular los contratos en operaciones petroleras. Ello solo servirá para facilitar la inversión en tal actividad.

Finalmente, consideramos que incorporar la práctica internacional y la jurisprudencia internacional permitirá promover la evolución de los contratos de inversión petrolera en nuestro país. La Lex Petróleadebe ser conocida, analizada y promocionada, a fin de dinamizar la contratación petrolera en nuestro país y mantenerla a la par de la evolución de ésta a nivel internacional. Este artículo pretende fijar un punto de partida en dicho intento por conocerla y difundirla, por lo que esperamos haber cumplido con dicho propósito. 